PONTIFÍCIA UNIVERSIDADE CATÓLICA DO RIO DE JANEIRO

\title{
As Expectativas da Geração Z Relativas à Inserção no Mercado de Trabalho
}

Felipe de Carvalho Ferreira de Salvo Souza

Trabalho de Conclusão de Curso

Centro de CIÊnCIAS Sociais - CCS

DEPARTAMENTO DE AdMINISTRAÇÃO

Graduação em Administração de Empresas 


\section{Felipe de Carvalho Ferreira de Salvo Souza}

\section{As Expectativas da Geração Z Relativas à Inserção no Mercado de Trabalho}

Trabalho de Conclusão de Curso

Trabalho de Conclusão de Curso apresentado ao programa de graduação em Administração da PUC-Rio como requisito parcial para a obtenção do titulo de graduação em Administração.

Orientador (a): Ana Heloísa Lemos 


\section{Resumo}

Souza, Felipe de Carvalho Ferreira de Salvo. As Expectativas da Geração Z Relativas à Inserção no Mercado de Trabalho. Rio de Janeiro, 2017. Número de páginas 31. Trabalho de Conclusão de Curso - Departamento de Administração. Pontifícia Universidade Católica do Rio de Janeiro.

A Geração Z se distingue das demais por nascer e crescer na era digital. Esses jovens ocupam cada vez mais o mercado de trabalho com o passar do tempo e, desta forma, vê-se necessário buscar conhecer e entender as características e expectativas que a Geração Z possui com o mercado de trabalho brasileiro. O objetivo do estudo é identificar qual a expectativa relativa à inserção no mercado de trabalho brasileiro que esses jovens possuem e consequentemente, entender se a atual situação do desemprego e da concorrência está impactando a expectativa desse jovem. As entrevistas foram realizadas presencialmente com jovens na faixa etária de 16 e 17 anos, estudantes do colégio privado São Vicente de Paulo localizado no Rio de Janeiro.

Palavras- chave: Geração Z; Mercado de Trabalho; Expectativa

\section{Abstract}

Souza, Felipe de Carvalho Ferreira de Salvo. The Generation Z Expectations Related to Labor Market Integration. Rio de Janeiro, 2017. Número de páginas 31. Trabalho de Conclusão de Curso - Departamento de Administração. Pontifícia Universidade Católica do Rio de Janeiro.

Generation $\mathrm{Z}$ is distinguished from the others generations by being born and growing in the digital age. These young people increasingly occupy the worklace over time and in this way, it is necessary to seek to know and understand the characteristics and expectations that Generation $Z$ has with the Brazilian labor market. The objective of this study is to identify the expectation regarding the insertion in the Brazilian labor market that these youngsters possess and consequently to understand if the current situation of unemployment and competition is impacting the expectation of this young folks. The interviews were conducted in person with young people in the age of 16 and 17, students of the private school São Vicente de Paulo in Rio de Janeiro.

Key-words: Generation Z; Workplace; Expectancy 


\section{Sumário}

1. Introdução 1

2. Referencial Teórico 4

2.1 Geração 4

2.1.1 Geração Z 5

2.1.2 Geração Z e o Mercado de Trabalho 7

$\begin{array}{ll}2.2 \text { O Novo Espírito do Capitalismo } & 10\end{array}$

$\begin{array}{lr}\text { 3. Metodologia } & 13\end{array}$

4. Apresentação e análise dos resultados 15

$\begin{array}{lll}4.1 & \text { Escolha do curso de graduação } & 16\end{array}$

$\begin{array}{lll}4.2 & \text { Inserção desejada no mercado de trabalho } & 18\end{array}$

4.3 Apreensões a respeito da inserção no mercado de trabalho 20

4.4 Avaliação das atuais mudanças na legislação trabalhista 22

5. Considerações Finais $\quad 24$

$\begin{array}{ll}\text { 6. Referências Bibliográficas } & 26\end{array}$ 


\section{Lista de Tabelas}

Tabela 1: Nascidos no Estado do Rio de Janeiro ........................................... 2

Tabela 2: Distribuição de área....................................................................... 2

Tabela 3: Atividade da Geração Z ............................................................... 8

Tabela 4: Preparação para o Mercado de Trabalho ............................................ 9

Tabela 5: Perfil dos Entrevistados ............................................................ 14 


\section{Introdução}

No Brasil, há uma instabilidade na esfera político-social e econômica que impactam o mercado de trabalho negativamente. A taxa de desemprego com 13,7\% em março de 2017, segundo a Pesquisa Nacional por Amostra de Domicílios Continua (PNAD), chegou a um dos piores índices com 14,2 milhões de desempregados.

Neste contexto, é importante o estudo sobre a Geração Z e o impacto no mercado de trabalho. Em virtude das mudanças político-sociais e econômicas, o desemprego e a instabilidade do mercado aumentam a quantidade de profissionais qualificados no mercado e com isto, menores chances de oportunidade fornecidas pelas empresas. Consequentemente a concorrência para a inserção ao mercado de trabalho aumenta (MCCRINDLE, 2014). Uma geração que almeja melhorar o relacionamento com o chefe, passa a ter uma maior intenção para o engajamento com o trabalho e não somente possuir o salário como propósito (ACCOUNTEMPS, 2015).

A geração é constituída, inicialmente, por conceitos centralizados no fator biológico de uma geração a outra, todavia, para maiores análises vê-se a necessidade de uma abordagem mais sociológica para a classificação das características específicas de uma determinada geração. A abordagem social abrange os eventos sociais, culturais, políticos, econômicos que um determinado grupo é exposto, buscando a distinção comportamental entre as gerações (COMTE, 1998; DIHTLEY, 1989 e MCCRINDLE, 2014).

A maior diferenciação da Geração $Z$ com as demais gerações é que os mesmos nasceram e cresceram na era digital, onde já havia internet e aparelhos tecnológicos, que se diferencia de todas as outras gerações que não foram expostas (TAPSCOTT, 1997 e MCCRINDLE, 2014). Ressaltando a importância de estudos voltados para Geração Z, para análise das características que possam derivar da exposição à internet e como essa mudança refletirá no mercado de trabalho.

Com grande peso demográfico, a Geração Z - 1995 até 2010 (MCCRINDLE, 2014) - está na fase do estudo ou da inserção ao mercado de trabalho brasileiro, 
todavia, com os recentes acontecimentos, esse jovem tende a passar a vida profissional prejudicada por não haver emprego no mercado e oportunidades para ganho de experiência.

Tabela 1: Nascidos no Estado do Rio de Janeiro

\begin{tabular}{|c|c|c|c|}
\hline $\begin{array}{c}\text { Nascidos no } \\
\text { Estado do RJ }\end{array}$ & Geração Z & Demais Gerações & TOTAL \\
\hline Pessoas & 4.970 .650 & 11.019 .279 & 15.989 .929 \\
\hline
\end{tabular}

Fonte: CENSO 2010, IBGE - Adaptado pelo autor.

Tabela 2: Distribuição de área

\begin{tabular}{|c|c|c|c|}
\hline $\begin{array}{c}\text { Distribuição de } \\
\text { Área }\end{array}$ & Urbana & Rural & TOTAL \\
\hline Pessoas & 4.792 .281 & 178.369 & 4.970 .650 \\
\hline
\end{tabular}

Fonte: CENSO 2010, IBGE - Adaptado pelo autor.

Segundo os dados do Instituto Brasileiro de Geografia e Estatística (IBGE), aproximadamente um terço da população do Estado é formada por jovens da Geração Z, observado na tabela 1, em consequência, encontrarão maiores desafios para inserção no mercado de trabalho. O meio urbano é onde parte majoritária da Geração Z reside, tendo a alta do desemprego, a concorrência aumenta e as oportunidades diminuem para essa geração.

Como forma de preparo com a concorrência, a Geração $Z$ aposta em uma graduação ou curso profissionalizante com respaldo de experiências profissionais para conseguirem inserção e um posicionamento estável no mercado (BRIEDGE RESEARCH, Geração Z, 2013). Observa-se a preocupação da Geração Z em procurar seu espaço no mercado de trabalho, assim como a preocupação das empresas em entender e receber a nova força de trabalho as novas características desta geração.

Para os autores do tema Geração Z, o estudo ainda é muito escasso no Brasil, mostrando a necessidade da iniciação de levantamento de dados através de pesquisas com a Geração $Z$ em foco para entender qual o hiato que a expectativa da Geração $Z$ possuí em relação à ausência de experiência profissional. Portanto, a relevância do estudo é justamente reforçar o levantamento de informação sobre a Geração Z para futuros trabalhos e 
entendimento sobre a distinção comportamental que ela possuí influenciada pela era digital.

A seleção de sujeito deste trabalho se constituiu de jovens com perfil crítico inseridos no grupo Coletivo do colégio privado São Vicente de Paulo, tendo em vista a necessidade de demonstrar um posicionamento analítico do tema abordado. $O$ entendimento e conhecimento sobre os atuais acontecimentos envolverão respostas com o atual posicionamento do Brasil, demonstrando o efeito da expectativa que a Geração $Z$ está exposta.

O Coletivo é um grupo formado pelos estudantes do colégio privado São Vicente de Paulo, que possui um perfil de mobilizador social, com posições críticas em temas voltados para a esfera político-social. Sua formação constitui uma característica rotativa espontânea para que mantenha a representatividade democrática dos alunos do colégio.

Observa-se que o aumento da concorrência e o desemprego afetam a expectativa relativa à inserção no mercado de trabalho. Desta forma, o estudo tem como objetivo levantar expectativas que influenciam a expectativa da Geração Z, buscando questionar quais as expectativas que os integrantes da Geração Z, com posicionamento político-social crítico, têm com relação à inserção no mercado de trabalho brasileiro. 


\section{Referencial Teórico}

\subsection{Geração}

A terminologia geração tem uma ampla gama de abordagens. Segundo Feixa e Leccardi (2010), Comte buscava um critério para a delimitação do conceito de geração, para que os estudos posteriores tivessem uma ferramenta sólida de pesquisa. Dessa forma, o tempo social foi associado à biologia do ser humano, fazendo com que um período de 30 anos fosse o necessário para uma geração substituir a outra.

Em contrapartida segundo os mesmos autores, Dilthey apresenta uma abordagem mais sociológica e menos biológica, afirmando que não é somente o tempo que define a qual geração o grupo pertence, mas também pelo conjunto de experiências que esse grupo compartilha.

De acordo com McCrindle (2014), autor do livro The $A B C$ of $X Y Z$, o termo geração é conceituado entre o nascimento dos pais e a geração dos seus filhos, em um período de 20 a 25 anos. Entretanto, com as mudanças demográficas e culturais da população, esse método de analisar a geração não se viu mais como satisfatório, sendo necessária uma abordagem mais sociológica, que une pessoas da mesma época impactadas pela cultura e identidade de determinado período de tempo. Mannheim (1952) acompanhado dessa mesma interpretação expande o conceito, mostrando que as gerações também têm o potencial para realizar transformações sociais.

Segundo Bauman, em Tempos Líquidos (2000), a sociedade no período da internet se tornou uma sociedade em rede, onde os pontos da rede podem se conectar e desconectar de ilimitadas formas. McCrindle (2014) ainda ressalta sobre a questão geracional que os jovens, inseridos na era digital estão conectados a gadgets no mundo todo. Do Brasil até a Austrália, da China até o Canada, temos uma generalização de acesso para os mesmos meios digitais de informação e influenciados pelas mesmas marcas - como Youtube e Google contextualizando características e a perspectiva que a geração passa a construir. 


\subsubsection{Geração Z}

De acordo com McCrindle (2014), a Geração Z é a nascida entre os anos de 1995 e 2009, correspondendo aproximadamente dois bilhões de pessoas ao redor do mundo. O termo foi cunhado a partir de uma analogia ao zapping, palavra inglesa cujo significado é o ato de mudar rápida e repetidamente de canal de televisão ou frequência de rádio. Tal relação provém da Geração Z ser contemporânea ao aparecimento de diversas tecnologias, principalmente a World Wide Web ${ }^{1}$, criada pelo físico britânico TimBerners-Lee em 1990.

Essa geração é exposta, por um período de tempo aos mesmos eventos sociais, políticos, econômicos e culturais, sendo a perspectiva desse determinado grupo moldada por características semelhantes. Todavia, McCrindle (2014) ressalta a importância de analisar as características de uma geração jovem, para distinguir a característica individual da geração, com a característica natural que todo jovem - por ser jovem - adquire, independente da geração pertencente.

Segundo o autor (McCrindle, 2014), existem sete fatores para definir a Geração Z:

1. Mudanças demográficas: $A$ Geração $Z$ vem crescendo em um ambiente de mudanças rápidas, tanto no âmbito tecnológico quanto no social. Uma das alterações importantes é a demográfica havendo grande impacto no que se refere ao envelhecimento da população, resultando em uma carreira, vida e aposentadoria em período maior de tempo.

2. Definição da geração: Essa geração nasceu em um período de recessão global, forte impacto pela globalização, que podemos perceber nas marcas e tecnologias presentes. Uma geração bemdotada de bens materiais, saturada pela tecnologia e globalmente conectada.

3. Integradores digitais: Os "Zeds" são integradores digitais nascidos em uma época tecnológica e quanto mais cedo estiverem ligadas à tecnologia, maior será o impacto dela em sua vida. Essa geração

1 Termo da língua inglesa que em português traduz-se literalmente por "Teia mundial", também conhecida como Web ou WWW, sendo um sistema de documentos em hipermídia que são interligados e executados na Internet. 
tem o primeiro contato com tecnologia antes mesmo de aprender a falar ou andar.

4. Focados globalmente: $A$ Geração $Z$ nasceu em um período de forte globalização, já conectados pelas mesmas marcas como Google, Youtube e Facebook, caracterizando a primeira geração com os mesmos impactos em âmbito global.

5. Visualmente engajados: Como os meios de comunicação vieram para vias digitais, o fluxo de informação cresceu em grandes proporções, dessa forma, as informações deram espaço a símbolos, marcas, imagens, vídeos, e cada vez menos palavras e frases.

6. Reforma educacional: A Geração Z tem maiores perspectivas para a educação superior, ultrapassando as estatísticas das gerações anteriores em número de membros com diplomas universitários. Assim como os estudantes mudaram, as escolas precisaram se adaptar a um modelo direcionado ao engajamento dos alunos em ambientes interativos.

7. Definição social: Devido à forte globalização e a internet, a Geração $Z$ é a mais conectada e com um maior poder de network do que as demais. Através de redes sociais, são capazes de moldar sua rede de contatos e mantê-las por maior tempo.

Tapscott, em seu livro, Grown Up Digital (2008), entende a geração da net ${ }^{2}$ como a primeira geração de fato nascida e criada no âmbito digital, com crianças aptas naturalmente a usarem a internet e os gadgets. Essa tendência de culturas difere das anteriores, podendo caracterizar-se como uma necessidade de adaptação com a nova forma de se relacionar que essa geração possui.

Segundo Tapscott, no livro Growing Up Digital (1997), há oito normas para caracterizar a Geração Z. A liberdade e customização são características dessa geração com a busca da sua individualidade, que seu relacionamento com a internet proporciona, a busca pela própria visão e opinião dentro de muitas vistas todos os dias nas mídias digitais. A Geração Z e procura por caminhos, produtos, serviços, voltados para sua diferenciação como indivíduo e o autoconceito. 
O escrutínio é uma característica marcante da geração exposta aos meios digitais, aonde há pouca regulamentação presente na legislação e opiniões, informações não verídicas são colocadas, fazendo com que eles adquiram esse mecanismo de análise minuciosa dentro da comunicação. Sendo uma geração que rapidamente percebe a comunicação com informações falsas ou não completas, sendo necessária uma abordagem mais limpa e clara para manter um diálogo eficaz.

As características integridade e colaboração que foram adotadas pela exposição à rede, com a chegada da mídia chegar aos mesmos sem filtragem e de forma instantânea a esses jovens, que assim percebem a necessidade de serem íntegros durante a sua comunicação com terceiros.

O entretenimento, velocidade e inovação são características ligadas à forma que a geração lida com o fluxo de informação que a internet possui, fazendo com que os mesmos - com forte traço multitarefa - necessitem de estímulos maiores em intensidade ou rápida inovação para manter o interesse e a curiosidade. Produtos e serviços são constantemente melhorados pelas empresas no intuito de reter a fidelidade e satisfação do seu cliente.

Esses oito fatores levantados por Tapscott abrem uma grande dúvida em relação como a Geração $Z$ irá absorver e aprender o legado deixado pela Geração Y. Sabe-se que, é a primeira geração nascida e crescida na era digital, e a forma como a Geração $Z$ pensa, relaciona-se, age e reage muda significativamente e tais mudanças terão que ser analisadas amplamente e minuciosamente para que haja a adaptação no gap cultural da Geração Z com suas gerações anteriores.

O mesmo ressalta Marc Prensky (2001) no artigo Digital Natives, Digital Immigrants, acrescentando que tal contextualização leva a um reflexo de uma individualidade distinta da Geração Z. Dessa forma, não há comportamentos contextuais comparativos com as demais gerações para predizer como essa individualidade distinta irá se posicionar dentro da sociedade.

\subsubsection{Geração Z e o Mercado de Trabalho}

Bauman, em a Modernidade Líquida (2000), interpreta uma mudança nos meios de trabalho, sendo vista anteriormente como uma forma sólida, de longo

2 Geração Net é uma terminologia usada pelo autor para caracterizar uma geração nascida no contexto digital. Terminologia alternativa para geração $Z$. 
prazo e objetivos duradouros, para uma forma líquida, de curto prazo e objetivos mais rápidos. O autor ressalta também o contexto do capitalismo pesado, a estrutura corporativa era de domínio e a falta de interesse na independência do trabalhador. A mudança ocorre para o capitalismo leve, voltado para o curto prazo, ações mais flexíveis, uma rotatividade maior dentro das corporações e os interesses do trabalhador, não mais limitado ao capital.

Essa mudança no capitalismo - presente no mercado de trabalho - são descritas por Nicole Eifler, psicóloga organizacional, em uma entrevista para a revista Human Resources Portugal (2010):

"Não só o comportamento dos colaboradores mudou como também as formas das organizações. Há algumas décadas podemos observar um achatamento das hierarquias. Isto significa que uma carreira tradicional, sendo linear, para muitos colaboradores isso não é possível. A carreira lateral, que também inclui mudar de empresa, é uma boa alternativa. A preocupação de muitos colaboradores é a possibilidade de desenvolvimento pessoal. Isto não significa apenas a subida da escala de carreira, mas também a ascensão de competências [...]”. (p. 27)

As mudanças no capitalismo segundo Bauman (2000) e as mudanças organizacionais de acordo com Eifler (2010) vão ter que se equilibrar com a principal característica da Geração Z, levantada por uma das maiores plataformas de vaga de emprego do Brasil, a Catho publicou em 2011, uma matéria descrevendo as características da Geração Z notificadas pelo suporte de dados da empresa. Sendo a principal execução de multitarefas, contrapondo o lado positivo a um lado negativo dentro dessa esfera. $O$ foco, assim como uma boa comunicação - são quesitos que mostram um lado negativo da característica multitarefa - que acarretam maior inconstância na Geração Z.

A pesquisa, Geração Z, realizada pelo Bridge Research (2013), com 1.101 entrevistados de 16 anos até 23 anos, levanta dados sobre a forma que a Geração Z, no Brasil, prepara-se para o mercado de trabalho:

Tabela 3: Atividade da Geração Z

\begin{tabular}{|c|c|}
\hline Tópico & Porcentagem \\
\hline Estuda e Trabalha & $45 \%$ \\
\hline
\end{tabular}




\begin{tabular}{|c|c|}
\hline Estuda & $34 \%$ \\
\hline Trabalha & $15 \%$ \\
\hline Sem Atividade & $6 \%$ \\
\hline
\end{tabular}

Fonte: Geração Z (2013), Bridge Research - Adaptado pelo autor.

Tabela 4: Preparação para o Mercado de Trabalho

\begin{tabular}{|c|c|}
\hline Tópico & Porcentagem \\
\hline Faculdade & $67 \%$ \\
\hline Curso Técnico & $32 \%$ \\
\hline Sem Preparação & $1 \%$ \\
\hline
\end{tabular}

Fonte: Geração Z (2013), Bridge Research - Adaptado pelo autor.

Com base nos dados da pesquisa (Bridge Research, Geração Z, 2013) observa-se que apenas $6 \%$ estão atualmente sem atividade e apenas $1 \%$ sem preparação para inserção ao mercado de trabalho - sem experiência educacional ou profissional. São dados baixos em comparação com os demais entrevistados, podendo afirmar que a Geração Z, caracteriza o preparo para o mercado através da realização de uma formação acadêmica ou técnica e que, buscam respaldar esse preparo com experiência profissional, refletindo os $45 \%$ dos entrevistados que trabalham e estudam.

Outra pesquisa, como a de Robert Half e Enactus (ACCOUNTEMPS, 2015) ressalta que, a Geração $Z$ é a segunda parte do grupo millennial ${ }^{3}$. Para avaliação dos valores e objetivos profissionais dessa geração, foi tirado como seleção de sujeito, um grupo entre 18 - 25 anos (já inseridos no mercado de trabalho) para realizar o levantamento de dados propícios para a pesquisa. $77 \%$ dos respondentes afirmaram que precisarão trabalhar com maior força de vontade que a geração anterior - $Y$ - para terem uma vida profissional satisfatória, o que mostra a conscientização dos jovens entre esforço versus recompensa.

No ambiente de trabalho, em relação à interação com o chefe, a Geração $Z$ busca um relacionamento de mentor e não a tradicional forma patrão e trabalhador, mostrando maior conscientização da geração na aprendizagem,

3 Termo usado para caracterizar o período temporal das gerações posteriores à geração X. Como geração Y, geração Z e geração Alpha. 
entretanto, também entende que o aprendizado pode vir de outras pessoas além do gestor, por isso $81 \%$ preferem trabalhar em equipe, pois é um mecanismo de compartilhar conhecimento e experiência em maior intensidade.

No quesito salário a prioridade para a Geração Z torna-se alta, entretanto, a conscientização dos valores éticos, como mostra 30\% deles, possui disposição em cortar de $10 \%$ a $20 \%$ do próprio salário caso haja engajamento com a missão da empresa. Assim fica claro na pesquisa que, mesmo com um bom salário, essa variável isolada não será motivo suficiente para a retenção dessa geração, e sim, combinada com outra variável para ajuda-las a atingir seus objetivos.

\subsection{Novo Espírito do Capitalismo}

No livro, O Novo Espírito do Capitalismo (2009), Boltanski e Chiapello, classificam o espírito do capitalismo como a ideologia por trás dessa interatividade entre o capitalista e o capitalismo. A característica principal do capitalismo é a acumulação ilimitada do capital, é a geração do lucro onde o dinheiro não deve ficar parado, seu objetivo é render e crescer.

Dessa forma, podemos analisar o consumo como fator importante para o fluxo do dinheiro e a geração de lucro, todavia, o baixo índice de consumo ou o consumo no conceito de necessidade, faz com que o capitalismo não chegue ao seu estado de máxima eficiência, pois seu acúmulo será limitado. O estímulo ao consumo é uma forma de influenciar o dinheiro circular dentro da sociedade e aguçar a geração do lucro e do valor.

Para as empresas, o capital inicial e o investimento são primordiais para alavancarem: empreendimentos que não obtêm o mesmo aporte financeiro; não alcançarem as mesmas chances de mercado. O colaborador segue o mesmo conceito, quem possuir um bom investimento em sua educação, cursos, atividades extracurriculares, terá maiores chances de crescimento profissional do que trabalhadores que não tiveram o mesmo nível de investimento - sendo ele privado ou público.

Pelo conceito dos autores, o capitalismo passa da autorregulação. A distinção entre os dois conceitos são percebidos através de o capitalismo estar além da autorregulação, pressupondo-se contratos, bancos, taxas, dentre outras atividades para sua atividade fim. Sendo a autorregulação e o senso comum fatores que impossibilitam a acumulação de lucro a qualquer método, por meio 
da legislação e leis de mercado, demonstrando o conceito da autolimitação do capitalismo ${ }^{4}$.

O estímulo à concorrência é uma forma da autolimitação do capitalismo, pois a maximização do lucro não será o único ponto de vista inicial, e sim a forma que poderá perder o consumidor e o lucro. A satisfação do cliente se torna também um ponto de vista central para empresas dentro do contexto competitivo, justamente para suprir sua principal função em geração de lucros.

Assim vê-se neste trabalho sobre as características da Geração Z, a integridade, a colaboração e a definição social (TAPSCOTT, 1997 e MCCRINDLE, 2014) são exemplos que dão um novo conceito cultural para o autolimite do capitalismo. O salário é um fator importante para Geração Z, entretanto, não é o único fator para a retenção dos trabalhos nas empresas (BOLTANSKI e CHIAPELLO, 2009). Percebe-se que a satisfação pessoal e profissional do trabalhador permeia além do salário, "[...] o salário constitui, no máximo, um motivo para ficar num emprego, mas não para empenhar-se" (BOLTANSKI e CHIAPELLO, 2009, p. 39).

O trabalhador almeja motivos sociais para sua satisfação pessoal, como constituir família e assegurar sua segurança e saúde, esses fatores torna a influenciar o engajamento da Geração Z com o mercado, consequentemente, influência o espirito do capitalismo. Boltanski e Chiapello (2009) pontuam três pilares para o espirito do capitalismo:

"[...] progresso material, eficácia e eficiência na satisfação das necessidades, modo de organização social ao exercício das liberdades econômicas e compatível com regimes políticos liberais". (p. 45)

O espírito do capitalismo é impactado pela cultura e a história local. A adaptação da nova geração com a cultura tradicional é o reflexo dessa mudança. A resistência à adaptação cultural, entre a geração anterior com a geração posterior, passa a ser considerada uma ameaça à identidade social e dessa forma, o conflito reflete o choque cultural. (BOLTANSKI e CHIAPELLO, 2009).

${ }^{4}$ Dentro da mudança ideológica do conceito do capital, a autolimitação se dá através da mudança na ética e moral dentro da sociedade. Contrapondo sua livre atividade de acúmulo ilimitado do capital. 
“[...] o capitalismo devia incorporar um espírito capaz de oferecer perspectivas sedutoras e estimulantes de vida, oferecendo ao mesmo tempo garantias de segurança e razões morais para fazer o que se faz" (p. 58).

Essa dualidade entre o espírito do capitalismo legitimar ou restringir o processo de acumulação, é pontuado através da cultura e da regulamentação do mercado para direcionar a legitimação dos processos. Entretanto, quando perde ou desvirtua-se deste espírito, volta ao conceito básico do capitalismo: acumulação de capital. Nesse contexto, "[...] nem todo lucro é legítimo, nem todo enriquecimento é justo, nem toda acumulação, mesmo grande e rápida, é lícita" (BOLTANSKI e CHIAPELLO, 2009, p. 58).

As justificações incorporadas pelo espírito do capitalismo estão na exposição clara dos objetivos almejados, com o intuito de fazer um determinado grupo compreender o funcionamento e realizar o engajamento do capitalista com o capitalismo segundo os mesmos autores acima citados. $O$ antagonismo dentro do espirito do capitalismo permeia entre o capitalismo conceitualmente permitir as mesmas oportunidades de acúmulo de capital a todos, com variáveis facilitando ou dificultando as chances de oportunidades. 


\section{Metodologia}

A seleção de sujeito do estudo foi constituída por seis jovens, com idades entre 16 e 17 anos, integrantes da Geração Z, com um perfil crítico políticosocial, sendo todos estudantes do tradicional colégio privado, São Vicente de Paulo, situado na Zona Sul do Rio de Janeiro e integrantes de um grupo denominado Coletivo. Este colégio frequentemente é palco de movimentos estudantis, como, manifestações na sacada pedindo paz, saúde e educação, contra o estupro, machismo e protestos contra atos de corrupção política no país.

Denominado Coletivo, o grupo tem uma estrutura de rotatividade para estimular o andamento das ideias e da participação de todos e nenhum dos entrevistados realizam alguma atividade profissional, todos finalizam seus estudos no ensino médio.

Para contemplar o objetivo de obter desses jovens as expectativas relativas à inserção no mercado de trabalho brasileiro, realizaram-se entrevistas presenciais com os entrevistados, em um espaço reservado para não criar ruídos nas respostas. Todos os entrevistados foram conscientizados sobre o propósito da entrevista e foi pedida a autorização dos mesmos para a coleta de dados.

As perguntas do roteiro permitiram que os entrevistados respondessem de forma original e livre em seus posicionamentos. O objetivo principal das entrevistas era fazer com que os entrevistados se sentissem confortáveis em falar abertamente sobre os tópicos abordados e obter respostas sem ruídos e de boa qualidade.

O roteiro foi planejado em dois blocos, o primeiro com seis perguntas para o levantamento do perfil do entrevistado. O segundo bloco, com dez perguntas abertas, buscou conhecer as expectativas dos entrevistados relativas à inserção de trabalho no mercado brasileiro. Abaixo se pode analisar o perfil de cada entrevistado: 
Tabela 5: Perfil dos Entrevistados

\begin{tabular}{|l|l|l|l|c|c|}
\hline Entrevistado & Gênero & Idade & Irmão & $\begin{array}{c}\text { Formação } \\
\text { da Mãe }\end{array}$ & $\begin{array}{c}\text { Formação do } \\
\text { Pai }\end{array}$ \\
\hline Entrevistado 01 & Masculino & 17 anos & 01 Irmã & Letras & Jornalismo \\
\hline Entrevistado 02 & Masculino & 16 anos & 01 Irmão & Economia & Matemática \\
\hline Entrevistado 03 & Feminino & 17 anos & 02 Irmãs & Psicologia & Administração \\
\hline Entrevistado 04 & Masculino & 17 anos & 04 Irmãs & $\begin{array}{c}\text { Educação } \\
\text { Física }\end{array}$ & Jornalismo \\
\hline Entrevistado 05 & Feminino & 17 anos & Nenhum & $\begin{array}{c}\text { Terapia } \\
\text { Ocupacional }\end{array}$ & $\begin{array}{c}\text { Jornalismo; } \\
\text { Administração }\end{array}$ \\
\hline Entrevistado 06 & Feminino & 17 anos & Nenhum & $\begin{array}{c}\text { Contabilidade } \\
\text { Direito }\end{array}$ \\
\hline
\end{tabular}

Fonte: Próprio autor (2017)

A composição do primeiro bloco, formado por seis perguntas foi: "Idade? "; "Gênero? "; "Possui irmão? O que fazem? "; "Formação e profissão da mãe?"; "Formação e profissão do pai?"; "Atualmente mora com quem?". A composição do segundo bloco, por meio de dez perguntas, foi "Você deseja realizar alguma graduação? "; "Qual graduação seria da sua escolha?"; "Por que desta escolha?"; "Você em algum ponto ficou com dúvida ou ainda está sobre a escolha da sua graduação?"; "O que influenciou para essa escolha final?"; "Como você gostaria que fosse sua inserção no mundo de trabalho, isto é, onde você gostaria de trabalhar? Por quê? "; "Você acha que vai conseguir essa inserção? Por quê? "; "O que mais the preocupa quando você pensa na sua entrada no mundo do trabalho? "; "O que mais lhe assusta quando você pensa no mundo do trabalho de hoje?"; "O que você acha sobre o modelo trabalhista anterior e o atual da terceirização?". 


\section{Apresentação e análise dos resultados}

Todos os entrevistados, com faixa etária de 16 e 17anos, estão matriculados no 3ํano do ensino médio e passam pelo processo do exame do vestibular, para que iniciem suas graduações e, assim, comecem sua inserção no mercado de trabalho brasileiro.

Nas respostas das entrevistas, nota-se um questionamento pessoal externo, (família, concorrência, mercado de trabalho, desemprego, rentabilidade e outros fatores), fatores que são discutidos normativamente entre os jovens, podendo considerar essas características relacionadas ao período juvenil (MCCRINDLE, 2014).

Observa uma elevada conscientização sobre responsabilidade civil e dos fatores que envolvem tomadas de decisão dos entrevistados, como o mercado de trabalho, instabilidade econômica, o desemprego e a alta concorrência, nas respostas apresentadas. Em suma, os desafios existentes à inserção do mercado, como boa formação universitária, atividade extracurricular, intercâmbio, domínio de línguas, dentre outros, são valorizados consideravelmente pelo desemprego e pela crise - fator revelado pelos entrevistados como um grande receio - aumentando assim, o padrão empresarial na avaliação dos critérios exigidos aos colaboradores.

O entendimento do impacto que o trabalho pode causar é mostrado através de desejos em achar um trabalho que equilibre qualidade de vida com um propósito pessoal, uma causa pelo qual o entrevistado se identifique e se sinta realizado. Mas há nas respostas, a dualidade entre o suprir a ideologia de um cargo de sucesso no mercado de trabalho e contemplar seu desejo por qualidade de vida. Assim como Tapscott (1997) ressaltou, com as características da Geração Z referentes à integridade e ao escrutínio, fazem com que esses jovens desenvolvam um perfil de maior senso crítico levando-os a um maior entendimento de si com o seu meio.

Os dados obtidos através da pesquisa foram analisados em quatro categorias de análise: "Escolha do curso de graduação"; "Inserção desejada no mercado de trabalho"; "Apreensões acerca da inserção no mercado de trabalho"; "Avaliação das atuais mudanças na legislação trabalhista". 


\subsection{Escolha do curso de graduação}

Todos os entrevistados afirmaram que pretendem fazer algum curso universitário. Esta resposta era previsível dado que os mesmos são jovens de classe média alta, alunos de um conceituado colégio privado e moradores da Zona Sul do Rio de Janeiro. Ademais, os pais de todos os entrevistados possuem formação superior, o que deve servir de modelo para os entrevistados. Seus irmãos também concluíram a graduação ou ainda percorrem este caminho, corroborando a influência dos pais e do meio em que foram socializados, nessa escolha. Tendo como essa seleção de sujeito, a reforma educacional citada por McCrindle (2014) não condiz com as respostas obtidas, uma vez que todos os familiares pertencentes à Geração X e Y são formados.

No que diz respeito à escolha do curso em si, a maioria dos entrevistados tem dúvidas com relação à escolha do mesmo. Eles alegam a dificuldade da escolha pelo fato da pouca idade.

A liberdade e a customização da Geração $Z$ derivada à exposição da internet enaltece a sensação de dúvida na escolha, tendo em vista que os entrevistados buscam profissões que também agreguem realização pessoal. A busca pela customização das características pessoais do entrevistado com as características do curso e sua especialização exalta também a sensação de dúvida (TAPSCOTT, 1997).

"Não sei ainda, quero tudo e quero nada ao mesmo tempo." (E03)

"Sim, ainda tenho dúvida já que é muito difícil ter convicção do que se quer fazer para a vida toda [...]" (E04)

A pouca idade faz com que tenham dúvidas de que o interesse atual, por um determinado curso se mantenha, nos próximos anos:

"Sim, tive dúvida entre Relações Internacionais e Direito, principalmente. Acho que não tenho mais dúvidas agora, mas não tenho certeza já que tudo pode mudar. " (E01) 
"[...] principalmente quando é um curso como medicina, que não tem tanto como fugir do tipo de trabalho que se faz, diferentemente de comunicação social, por exemplo, que é mais amplo. " (E04)

Ademais, há entrevistados que ainda não têm clareza com relação ao curso escolhido, por não saber diferenciá-lo de outro que considera similar.

"Sim, já tive dúvida entre biologia marinha, por exemplo. Mas dentro da comunicação social ainda tenho. " (E06)

"Já tive bastante dúvida entre economia e engenharia, por causa da matemática. " (E02)

Em alguns casos, apesar dos entrevistados estarem certos da escolha por um determinado curso, ainda não sabem qual área seguir, dentro dessa formação:

"Não sei ainda. Talvez engenharia de produção ou administração. " [...] "São duas opções que me atraem. Gosto de matemática também, isso ajuda, mas não é o principal. Acho que gostar só da disciplina envolvida não quer dizer nada. Os cursos abrangem muito mais que isso. " (E04)

"Mas dentro da comunicação social ainda tenho dúvida" (E06)

A escolha do curso foi, para muitos, influenciada por salário, qualidade de vida, estabilidade, habilidades pessoais, temas abordados no colégio ou com os pais, visita a campus de faculdades, palestras dos alunos de determinada graduação e testes vocacionais. Tendo em vista pesquisas que ressaltam a prioridade da Geração Z no quesito salário, possibilita vincular dois dos três pilares do espirito do capitalismo: progresso material e eficácia e eficiência na satisfação das necessidades refletindo a qualidade de vida e estabilidade 
desejada dos entrevistados. (HALF e ENACTUS, 2015; BOLTANSKI e CHIAPELLO, 2009).

"O que mais me influenciou foi minha tendência à criação. Ouvir das pessoas que tem tudo a ver comigo e que eu iria gostar. Conhecer o campus da faculdade e ouvir alunos de comunicação social ajudou bastante. " (E06)

"Um bom salário e estabilidade" (E05)

"Modelos de simulação da ONU e testes vocacionais por uns cinco meses. " (E01)

Uma das entrevistadas, cuja família passa por dificuldades financeiras, mostrou-se hesitante em sua escolha, em função da remuneração revelando um aspecto abordado na literatura, o fato da Geração Z ter nascido inserida na crise econômica e político-social, o que enfatizou seu desejo por estabilidade e bons salários (MCCRINDLE, 2014).

"Ainda não sei o que quero, mas considerando as opções, acho que o fato de me atrair mais que as outras, o salário e a condição de vida influenciam bastante. " (E04)

\subsection{Inserção desejada no mercado de trabalho}

No quesito da inserção desejada, os entrevistados divergem entre o setor público e o setor privado. Todavia, a quebra da confiabilidade com o setor público - devido aos acontecimentos recentes no Brasil - faz com que os mesmos mudem o interesse para o setor privado. Observa-se um dos fatores expostos na literatura, o escrutínio, levando os jovens a uma maior sensibilidade crítica das informações passadas e, a um entendimento melhor dos fatos apresentados pela sua minuciosa percepção (TAPSCOTT, 1997).

"A ideia era trabalhar em um setor público, mas nesse momento o melhor seria em uma empresa privada. $O$ 
Estado está quebrado; os setores públicos não estão se sustentando. " (E04)

"Queria trabalhar em alguma iniciativa privada, para fazer alguma coisa inovadora para o mundo. Não quero ficar na mesmice de fazer a mesma coisa para sempre, quero inovar. " (E02)

"Gostaria de trabalhar em um hospital público, pois acho que é uma das partes mais importantes do "ajudar as pessoas". Não sei se um hospital privado traria a mesma satisfação. " (E05)

A convicção mostrada pelos entrevistados sobre a sua futura inserção ao mercado de trabalho está vinculada à boa formação, autoconfiança e ao nível de concorrência de sua determinada área.

"Acho que sim, acredito no meu potencial. Tenho uma boa formação e condição de vida para ingressar em uma boa faculdade e correria muito atrás disso, e confiaria no meu trabalho. " (E06)

"Acho que sim, pois acredito que tem uma tendência dos médicos formados a quererem residência em hospitais particulares, já que agora a esfera pública está sendo desvalorizada. Então talvez nisso não seja tão concorrido o concurso. $E$ também porque pretendo estudar o necessário para isso. " (E05)

"Espero que sim. Acho que se eu me esforçar e botar a cabeça no que eu quero eu consigo alcançar o que eu preciso. " (E02)

A realidade da meritocracia no mercado de trabalho brasileiro é refletida nas respostas dos entrevistados, que percebem que determinados fatores são um acréscimo para a superação da concorrência, o aporte de uma boa e 
tradicional escola privada, contatos de determinados setores e condição de vida para investimento educacional são exemplos que minimizam a concorrência.

"Se eu fizer uma dessas opções acho que consigo, acredito que tenho capacidade. Certos contatos são importantes também, e estudei sempre em uma boa escola. " (E04)

"Tenho uma boa formação e condição de vida para ingressar em uma boa faculdade [...]" (E06)

"[...] porque tenho uma formação boa, sempre estudei em escola boa e provavelmente se eu não conseguir passar para uma federal, vou ter recurso para fazer uma faculdade boa então acho que a questão mesmo é a saturação do mercado. " (E03)

\subsection{Apreensões a respeito da inserção no mercado de trabalho}

Os entrevistados demonstraram determinadas apreensões nas respectivas respostas. As de maior incidência são a concorrência do mercado, a alta taxa de desemprego - que proporciona maior concorrência - o ambiente de trabalho e a desvalorização do setor público. Demostrado na literatura por McCrindle (2014), o desemprego impactará gradualmente na definição social dessa geração, uma vez que exalta insegurança e medo na Geração $Z$ devido ao aumento da concorrência, podendo refletir em seu caminho profissional.

"A quantidade de gente para uma coisa só. A concorrência.

O ambiente de trabalho também, flexibilidade de carga horária e mobilidade" (E04)

"Justamente a desvalorização do setor público; em como vai estar o SUS ${ }^{5}$ e as universidades públicas. " (E05)

${ }^{5}$ O Sistema Único de Saúde (SUS) foi criado em 1988 pela Constituição Federal Brasileira com o objetivo de qualificar o sistema público de saúde. 
"O que mais me preocupa é a concorrência. Principalmente dentro dessa esfera, o que mais tem é gente criativa com ideia nova para o mercado. Minha preocupação é não me sobressair em meio a toda essa gente, e não despontar. Ficar na média. " (E06)

Um entrevistado, em particular, não compartilha das preocupações que os demais entrevistados apresentaram. A literatura apresenta o fator integridade como característica da Geração Z, podendo-se observar na resposta do entrevistado a integridade pessoal e a integridade cívica respectivamente (TAPSCOTT, 1997).

"Me preocupa se eu vou gostar de verdade, só isso, porque o Itamarati traz muita segurança[...] As responsabilidades e as injustiças. " (E01)

Ainda sobre as apreensões com o mercado de trabalho brasileiro, os entrevistados falaram do desemprego e saturação do mercado. Na literatura nota-se o respaldo dessas apreensões mostradas pelos entrevistados, exaltando que a cultura contemporânea - instabilidade na esfera político-social e econômica - infere na justificativa do capitalismo, que possui o objetivo de acumular capital (BOLTANSKI e CHIAPELLO, 2009).

"O alto número de desempregados e a alta saturação em diversos setores da sociedade." (E02)

"A saturação do mercado. " (E04)

"A instabilidade da economia, os desempregos. A saturação do mercado e as relações trabalhistas. " (E06)

Um dos entrevistados vai além da preocupação com o desemprego e a saturação e se preocupa com questões do âmbito social entre proletariado e o capital. 
"Que algumas pessoas podem perder emprego do dia pra noite, que algumas leis podem ser aprovadas e facilitar isso mais ainda, tornar cada vez mais difícil a vida do trabalhador. " (E05)

\subsection{Avaliação das atuais mudanças na legislação trabalhista}

Em sua grande maioria, os entrevistados apresentaram preocupações em relação à perda dos direitos trabalhistas já conquistados. Há uma quebra de confiabilidade entre o indivíduo e os trâmites legislativos, uma vez que os mecanismos de autorregulação, demonstrados na literatura, foram expostos à desfuncionalidade dos respectivos processos regulatórios (BOLTANSKI e CHIAPELLO, 2009).

"Acho que, sobre o modelo sem as modificações, a conquista da CLT teve uma garantia de direitos que agora tão sendo ameaçados, então tem uma série de questões e propostas pela reforma trabalhista de você poder terceirizar a atividade fim [...]" (E03)

"Eu acho que desde o inicio do século houve um progresso nas relações trabalhistas, com mais direitos ao trabalhador, benefícios e aumento razoável de salário mínimo. Com a terceirização e a reforma das leis trabalhistas isso pode se perder e isso seria muito ruim." (E05)

"Os direitos do trabalhador são sagrados para estabelecermos uma sociedade mais justa comparado ao que vivemos. Se o Estado não garante para o empregado tais direitos fundamentais, não é o patrão ou o empresário que vai garantir. O lucro prevalece, pois vivemos em uma sociedade capitalista, movida por essas relações." (E06)

Entretanto, também concordam que o modelo antigo estava ultrapassado e necessitava de reformas, mas a maioria dos entrevistados discorda da forma que a atual reforma está sendo realizada. 
"Estava ultrapassado, necessitando de reformas, mas não dessa forma que está sendo feita. O mercado mudou e as leis não o acompanharam, mas as medidas tomadas foram retrógradas, retirando direitos. Estamos falando de mais poder para os patrões. Isso é perigoso, não vai favorecer o trabalhador. Tinha que mudar, mas desse jeito, era melhor antes, mesmo ultrapassado, do que dessa forma." (E04)

"Acho que o atual agrega muitos direitos conquistados, e com a terceirização e outras medidas teremos esses direitos sendo retirados. Muito ruim, pelo o que tá sendo feito e da forma que tá sendo feito." (E02)

"Eu acho que desde o inicio do século houve um progresso nas relações trabalhistas, com mais direitos ao trabalhador, benefícios e aumento razoável de salário mínimo. Com a terceirização e a reforma das leis trabalhistas isso pode se perder e isso seria muito ruim." (E05)

Um dos entrevistados, através da sua resposta, demonstrou concordar com a atual revisão do modelo trabalhista, podendo ressaltar a influência da formação dos pais que são economista e matemático.

"Eu acho que é muito ultrapassado, e a terceirização e essa mudança nas leis trabalhistas são um passo inicial pra flexibilizar e ajudar algumas pessoas a ingressar no mercado de trabalho sem grandes dificuldades." (E02) 


\section{Considerações Finais}

O objetivo do estudo foi o levantamento das expectativas relativas à inserção ao mercado de trabalho brasileiro pela Geração Z, dado o contexto instável das esferas econômica e político-social do país. Observando-se os fatores concorrência e desemprego abordados pelos entrevistados e de que forma impacta em suas respectivas expectativas.

Todos os entrevistados apresentaram interesse na realização de uma graduação, demonstrando conscientização da importância dessa tomada de decisão. Condizendo com o estudo do autor apresentado no referencial teórico sobre a educação da Geração Z, que busca esse foco com maior afinco que as demais gerações, podendo ou não estar diretamente ligado ao período de recessão global (MCCRINDLE, 2014).

Nas respostas obtidas pode-se observar as características levantadas por Tapscott (1997), a liberdade e a customização, que os entrevistados apresentaram na escolha da determinada graduação, demonstra que os mesmos apesar de priorizarem o salário e a estabilidade, preocupam-se em adaptar motivações pessoais com profissionais - customização - e demonstram interesse em uma vida profissional com diferentes diretrizes e diferentes empresas, exemplificando a dualidade entre salário e valores pessoais (TAPSCOTT, 1997 e ACCOUNTEMPS, 2015).

A pesquisa ressalta ser possível perceber que a concorrência e 0 desemprego são expectativas estimulantes para a apreensão dos mesmos em relação ao mercado, fatores que são exaltados pela instabilidade no país e que fazem essa geração adaptar sua percepção da situação. Na literatura, observase a exposição que a Geração $Z$ está no Brasil irá impactar sua definição de geração e definição social (MCCRINDLE, 2014).

Para que se sobressaiam nesta concorrência aumentada pelo desemprego e alcancem a estabilidade, os entrevistados demonstraram apostar em uma formação de qualidade, alinhados com a pesquisa sobre a Geração Z no Brasil, mas não se pode afirmar o respaldo por experiência profissional mostrado pela pesquisa da Bridge Research, devido que os entrevistados não possuem experiência profissional (2013). 
O estudo mostra que os entrevistados, pertencentes à Geração Z, possuem apreensões influenciadas pela atual conjuntura econômica e políticosocial. A falta de vagas proporcionada pelo mercado de trabalho e a alta da concorrência infligem diretamente na confiança desses jovens, refletindo nas expectativas que os mesmos possuem com o mercado de trabalho.

O fator que estimula a insegurança da Geração Z, apresentada nas respostas, é a mudança na legislação trabalhista. Apesar de concordarem que necessitava de reforma, não concordam com a forma que proposta esta sendo implementada. O mercado de trabalho é um fator novo não experimentado por esses jovens, permitindo aos mesmos a sensação de insegurança e nervosismo. A mudança na legislação faz com que esses jovens não consigam se imaginar inseridos dentro da nova implementação, aumentando a sensação de insegurança e nervosismo entre eles.

Deste modo a insegurança poderá refletir em seu perfil profissional, como através da ansiedade, alta cobrança pessoal, culpabilidade, autossabotagem, dentre outras emoções que possam dificultar o completo desenvolvimento desses profissionais. As empresas possuem um grande desafio para estimular a Geração Z em seu desenvolvimento em tal contexto, almejando uma produtividade de excelência.

O estudo demonstra a importância de entender e estudar a Geração Z por sua característica única em relação com as demais gerações (nascidas e criadas na era digital). Podendo haver características e mudanças imprevisíveis com o seu meio, dado que é a primeira vez que a sociedade passa por essa situação em que uma geração é altamente exposta à internet (TAPSCOTT, 1997).

Vê-se que tais características moldam o novo espirito do capitalismo, influenciado pela cultura e pelos eventos locais, impactando diretamente no mercado de trabalho (BOLTANSKI e CHIAPELLO, 2009). A importância desse estudo leva em consideração a necessidade empresarial em adiantar-se a essas características para começarem o processo de adaptação à nova força de trabalho, como recrutar, reter, treinar, desenvolver esses jovens e torná-los um ativo importante para a empresa, assim, evita-se a perda de competitividade empresarial e de oportunidades perdidas. 


\section{Referências Bibliográficas}

MCCRINDLE, M. The ABC of XYZ: Understanding the global generations. Bella Vista: McCrindle Research, 2014.

Instituto Brasileiro de Geografia e Estatística. Censo Demográfico: Síntese de indicadores 2010. Rio de Janeiro, 2010 Disponível em: < http://www.ibge.com.br/>. Acesso em: 13 de Março 2017.

ACCOUNTEMPS. Generation Z: Five Surprising Insights. Menlo Park, 2015. Disponível em $<$ http://accountemps.rhi.mediaroom.com/index.php?s=189\&item $=1751>$. Acesso em: 31 de março de 2017.

Between us, the generations. In LARROSA, J. On generations: On coexistence between generations. Barcelona: Fundació Viure i Conviure, 2007.

Bridge Research. Geração Z. São Paulo, 2013. Disponível em < http://www.bridgeresearch.com.br/dv_files/arquivos/20150730112426_dbarquivo s.pdf>. Acesso em: 28 de Abril de 2017.

TAPSCOTT, D. Growing Up Digital: The ride of the Net Generation. McGrawHill: Tapscott Research, 1997.

TAPSCOTT, D. Grown Up Digital: How the Net Generation is changing your world. McGraw-Hill: Tapscott Research, 2008.

A Geração Z e o mercado de trabalho. Human Resources Magazine, Portugal, agosto. 2010. C.4, p. 27.

BAUMAN, Z. Modernidade Líquida. Rio de Janeiro: Jorge Zahar, 2001.

BOLTANSKI e CHIAPELLO. O Novo Espírito do Capitalismo. França, 2009.

PRENSKY, M. Digital Natives, Digital Immigrants. On the Horizon: MCB University Press, v. 9, n.5, p. 01-06, 2001.

Instituto Brasileiro de Geografia e Estatística. Pesquisa Nacional por Amostra de domicílios: Síntese de indicadores 2015. Rio de Janeiro, 2015 Disponível em: < http://www.ibge.com.br/>. Acesso em: 13 de Março 2017.

MANNHEIM, K.; DE LA YNCERA, I. S. El problema de las generaciones. Revista Española de Investigaciones Sociológicas (REIS), n. 62, p. 193-242, 1993.

BAUMAN, Z. Tempos Líquidos. Rio de Janeiro: Jorge Zahar, 2000. 